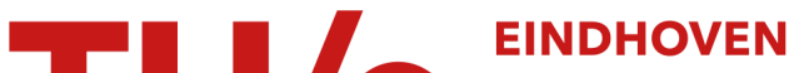 \\ UNIVERSITY OF \\ TECHNOLOGY
}

\section{Car drivers' compliance with route advice and willingness to choose socially desirable routes}

\section{Citation for published version (APA):}

Kerkman, K. E., Arentze, T. A., Borgers, A. W. J., \& Kemperman, A. D. A. M. (2012). Car drivers' compliance with route advice and willingness to choose socially desirable routes. Transportation Research Record, 2322, 102-109. https://doi.org/10.3141/2322-11

DOI:

10.3141/2322-11

Document status and date:

Published: 01/01/2012

\section{Document Version:}

Accepted manuscript including changes made at the peer-review stage

\section{Please check the document version of this publication:}

- A submitted manuscript is the version of the article upon submission and before peer-review. There can be important differences between the submitted version and the official published version of record. People interested in the research are advised to contact the author for the final version of the publication, or visit the $\mathrm{DOI}$ to the publisher's website.

- The final author version and the galley proof are versions of the publication after peer review.

- The final published version features the final layout of the paper including the volume, issue and page numbers.

Link to publication

\section{General rights}

Copyright and moral rights for the publications made accessible in the public portal are retained by the authors and/or other copyright owners and it is a condition of accessing publications that users recognise and abide by the legal requirements associated with these rights.

- Users may download and print one copy of any publication from the public portal for the purpose of private study or research.

- You may not further distribute the material or use it for any profit-making activity or commercial gain

- You may freely distribute the URL identifying the publication in the public portal.

If the publication is distributed under the terms of Article 25fa of the Dutch Copyright Act, indicated by the "Taverne" license above, please follow below link for the End User Agreement:

www.tue.nl/taverne

Take down policy

If you believe that this document breaches copyright please contact us at:

openaccess@tue.nl

providing details and we will investigate your claim. 


\section{Car Drivers' Compliance with Route Advice and Willingness to Choose Socially Desirable Routes}

\section{Kasper Kerkman}

Faculty of Architecture, Building and Planning

Urban Planning Group

Eindhoven University of Technology

The Netherlands

E-mail: k.e.kerkman@aluminus.tue.nl

\section{Theo Arentze*}

Faculty of Architecture, Building and Planning Urban Planning Group

Eindhoven University of Technology

The Netherlands

tel. +31 402472283

fax +31 402438488

E-mail: t.a.arentze@bwk.tue.nl

\section{Aloys Borgers}

Faculty of Architecture, Building and Planning Urban Planning Group

Eindhoven University of Technology

The Netherlands

E-mail: a.w.j.borgers@bwk.tue.nl

\section{Astrid Kemperman}

Faculty of Architecture, Building and Planning

Urban Planning Group

Eindhoven University of Technology

The Netherlands

E-mail: a.d.a.m.kemperman@bwk.tue.nl

* Corresponding author

Submission date: March, 2012

Word count: $6176+5$ figures and tables

Submitted for publication to

Transportation Research Board

$91^{\text {st }}$ Annual Meeting, January 2012

Washington, D.C. 


\begin{abstract}
This study describes the results of a stated choice experiment conducted to analyze route choice behavior of car drivers under influence of advice and feedback on environmental consequences of their trips. Framing of the route advice is varied in terms of goal of the agency providing the advice (system or individual optimality) and extent to which it is generic or tailored to the specific preferences of the person. The findings suggest that, under conditions of rich information about attributes of choice alternatives, advice is discarded when it is supposed to serve the driver's own interests and information allows the individuals to evaluate outcomes independently, but is taken into account when it is said to serve traffic management objectives. In line with expectations, the impact of advice is larger when it is labeled as personal compared to when it is labeled as generic. An interesting finding is that the impact of advice on evaluations of route alternatives is not uniform across attributes. Whereas some attributes become suppressed in the evaluation, others become more salient. The study further provides evidence that travelers are willing to trade-off social objectives against individual-level objectives. We discuss the implications of these findings for the design and use of travel information systems as an instrument for traffic management and identify problems for future research.
\end{abstract}

Keywords: route choice, advanced travel information systems, compliance behavior, prosocial behavior, traffic management, environmental impacts. 


\section{INTRODUCTION}

Advanced Travel Information Systems (ATIS) are generally seen as an important instrument to alleviate traffic congestion problems that exist almost all around the world. Either by providing up-to-date information about traffic conditions or directly by providing route guidance, the systems can assist car drivers in avoiding congested links of the road network and, in that way, contribute to a better distribution of traffic and, hence, a better use of existing road capacity. However, the massive use of especially in-vehicle navigation systems also appears to have detrimental effects. Typically, the systems guide users through the fastest route to their destination. In the Netherlands, for example, this has led to an increase of traffic that runs through built-up area where it causes nuisance for local inhabitants in terms of noise, air pollution and increased risk of traffic accidents. Whether or not triggered by this situation, providers of navigation systems and route planners have started to acknowledge that travelers' preferences involve a broader set of criteria than just travel time. New generations of the systems offer route alternatives, such as a most economic route or a most scenic route, allow users to enter their preferences for particular road types (i.e., higherlevel roads) and provide feedback in terms of environmental impacts of trips.

Little is known about what the likely impact of the new developments will be for route choice behaviour. There is a large body of literature on the use and influence of ATIS on travel behaviour. Chorus et al. (1) provide a comprehensive overview of this area. Theoretical studies on the potential of network effects of ATIS typically assume full compliance or some pre-defined rate of compliance. A second stream of research has considered compliance behavior from an empirical perspective. These studies have provided valuable insights in which factors affect travelers' propensity to follow advice and how big the influences of these factors are on compliance. A consistent finding is that experienced accuracy of information is a dominant factor in drivers' compliance behavior $(2,3,4,5,6)$. Compliance drops dramatically when wrong information is obtained. Travel time variability, experienced late arrivals, perceived switching costs and network familiarity are also found to play a role (1).

Compliance behavior has predominantly been studied in the context of uncertainty about travel time and information quality. Travelers' do however not necessarily act only in their own interest. In situations where there is a discrepancy between what is best for the system (society) as a whole and what is best for the person individually, the traveler faces a social dilemma to the extent that he/she is aware of that discrepancy. Several studies have shown that individuals across various areas of travel choice are willing to take into account negative environmental or social consequences of their trips when such consequences are brought to their awareness $(8,9,10,11)$. Pro-social behavior is apparent, for example, in willingness of individuals to participate in programs or accept policies that are aimed at promoting environmental friendly modes of travel (e.g., car pooling). In the area of route choice, awareness of conflicting interests tends to be enhanced by route planners and navigation systems that provide feedback on environmental consequences of travel choices. This means that trading-off social/system objectives against personal objectives increasingly becomes a factor in route choice behavior.

In this study we address car drivers' compliance with route advice and willingness to take social objectives into account under the rich information conditions new generations of travel information systems provide (in pre-trip or en-route stages). In particular we test the impact of specifications of the source of advice. Theoretical analysis conducted by Chorus et al. (7) indicates that, in decisions to comply with advice, a rational decision maker takes into account the objectives of the agency providing the advice and the extent to which advice takes into account specific preferences of the individual. Framing of information on 
compliance behavior has received some attention in the literature. However, existing studies have focused on format dimensions of information, such as prescriptive (advice) versus descriptive information, predictive versus historic information and quantitative versus qualitative information (1). An exception is Han et al. (12). They considered the impact of the objective of the information provider on route choice. In a stated choice experiment, they varied the label of route advice in terms of objective of guidance such as welfare maximization, equal capacity use and user equity. They found an impact of the label. However, they were primarily interested in strategic behavior of drivers and, therefore, controlled compliance rates as background variable in the experiment as well. We hypothesize that compliance decreases when advice serves goals of traffic management (i.e., is focused on achieving optimal distribution of traffic) rather than the individual's own interests (e.g., the fastest route) and increases when it is personalized rather than generic. To test these hypotheses, we conduct a stated choice experiment where individuals indicate their route choice under particular advice conditions.

The remainder of this paper is structured as follows. First, in Section 2 we describe the design of the experiment. Then, in Sections 3 and 4 we discuss the sample and results of the experiment. In the last section we conclude the paper by discussing the major conclusions and directions for future research.

\section{ROUTE CHOICE EXPERIMENT}

The participants of the stated choice experiment are asked to choose between two imaginary routes. Using the stated choice experiment technique, the attributes of choice alternatives, source of advice as well as relevant context variables are varied based on an orthogonal design. The choice experiment mimics an information rich situation where a travel information system consistently shows several route alternatives and provides (quantitative) information about the attributes of alternatives, including impacts on the environment.

\section{Advice conditions}

As methods to regulate the future traffic flows, such as dynamic traffic management, are likely to use some sort of route advice to control the traffic situation, the compliance with the route advice from traffic management is a relevant topic. By adding an attribute for different types of advice in the stated choice experiment, the importance of a route advice can be measured and compared with the other route choice attributes. To tests our hypotheses, we varied the following route-advice conditions:

1. No advice

2. Traffic management, generic advice

3. Traffic management, personalized advice

4. Navigation system, generic advice

5. Navigation system, personalized advice

Participants of the experiment are explained that traffic management is concerned with controlling traffic in a way that is optimal for the system (distributing traffic such that bottlenecks are prevented), whereas the navigation system only considers what is optimal for the user. On another dimension the advice differs in terms of the extent to which the agency is supposed to take specific preferences for routes of the user into account. In case the advice is generic, it does not, and in case it is personalized it does. As explained to respondents, generic advice means that the recommending agent (in-car navigation system or traffic 
manager) has no information about the specific preferences of the person under concern and, hence, uses average preferences of car drivers in terms of trading-off different objectives such as lowest costs, shortest time and most convenient in making route choices. The no-advice condition is the control condition. Each respondent is randomly allocated to either one of these experimental conditions. This set-up allows us to test the hypotheses that advice has bigger impact when the information system intends to serve the interests of the individual and considers his/her specific preferences.

The advice condition is implemented by randomly assigning a recommendation status to one of the two route alternatives in each presented choice-set. This allows us to measure the degree of compliance as an overall scale effect on the influence (utilities) of route attributes on choice: if respondents ignore the advice completely than attributes have the same influence as in case of no advice (scale equals one). On the other hand, if respondents always comply with the advice than the attributes have no influence on the choice (scale equals zero). If respondents only partly comply with advice then the scale will lie somewhere in between zero and one. The exact value of the scale provides a measure of the degree of compliance. In the experiment, the user does not get feedback on outcomes of choices. Such feedback is not considered relevant here, given that we are interested in users' response to the nature of different forms of advice rather than experienced quality of the advice.

\section{Route attributes}

The route attributes used in the experiment are the dimensions on which users receive information from an imaginary information system. The dimensions are chosen in such a way that they cover considerations that tend to play a role in route preferences, as revealed in earlier studies $(13,14,15,16,17)$, and can be displayed in an information system. Furthermore, the impact of a trip in terms of nuisance caused for the environment was included to test the extent to which individuals are willing to trade-off social objectives against individual-level objectives.

We assume that in addition to conventional quantitative attributes, such as travel time (minutes) and costs (Euros), also more qualitative attributes, like comfort and scenery, potentially play a role in route preferences. Since by definition the qualitative attributes are harder to quantify, the levels of these attributes are shown using a label, comparable to the European Union A-F energy label system commonly used to display energy efficiency of consumer products like refrigerators, washing machines and cars. Where A means very high quality and $\mathrm{F}$ means very low quality on the dimension concerned. The labels allow participants of the experiment to interpret the levels of the attributes in a quick and intuitive way ${ }^{1}$.

The following attributes are used in the experiment:

- Travel time: estimated travel time when there are no delays.

- Estimated delay: predicted extra travel time due to traffic congestion.

- Trip costs: costs defined as sum of fuel costs and a possible road price.

- Comfort: degree of comfort determined by the number of stops, turns, and intersections on the route and expressed by a quality label (A-F label system).

\footnotetext{
${ }^{1} \mathrm{~A}$ downside of this approach is that the exact value of the labels is not clear, as they are based on the interpretation of the participants. In a subexperiment, therefore, we asked respondents to assign labels to routes that were systematically varied on readily observable characteristics of routes for each of the distinguished dimensions. In this paper, we focus on the results of the main experiment.
} 
- Scenery: attractiveness of the landscapes the driver passes through and views along the route, expressed by a quality label (A-F label system).

- Environment and burden: the degree to which the route causes nuisance for local inhabitants as unwanted traffic (A-F label system).

- Safety: degree of safety for the driver determined by presence of intersections, separate lanes, mixed traffic, speed differences and crash barriers (A-F label system).

The levels chosen for the attributes (Table 1) are realistic for local urban trips. Road pricing is not an existing policy in the Netherlands. However, respondents can easily imagine this as it was part of a much debated national policy plan in the Netherlands until recently. Since road pricing conditions tend to vary depending on location, it is not a violation of perceptions of reality that travel time and travel costs are varied independently in the experiment. The qualitative as well as quantitative attributes are clearly explained to participants by means of instruction text to avoid ambiguity in interpretations. For the qualitative attributes only 3 out of 5 levels were varied being labels $\mathrm{A}, \mathrm{C}$ and $\mathrm{E}$.

<insert Table 1 around here>

The rich information condition mimicked in the experiment means that the expected influence of route advice in the experiment as well as reality when these conditions become common place should be tempered. Since the individual has the information needed to evaluate route alternatives on important attributes (time, costs, etc.), he/she can safely ignore the advice and determine his/her own preference if the advice obtained is supposed to serve the individual's own preference (the navigation system). Thus, we expect a small effect of advice in the condition where it is said to originate from the navigation system. Only in case an individual would use it to save the mental effort of evaluating the alternatives it will influence his or her behavior. Thus, the response to this experimental condition reveals the extent to which individuals are inclined to blindly follow advice. A word of caution is in place here. Since a recommendation is assigned randomly it may occasionally be assigned to alternatives that are underperforming on the shown attributes. When being noticed, poor performance of the advice may lead the individual to disregard it. Also for this reason we expect a weak response to the navigation-advice condition. Note however that we hit here an inherent difficulty of measuring compliance behavior under rich information conditions: if advice correlates strongly with own evaluations, we cannot disentangle the separate influence of advice from preferences and if it does not correlate with preferences it might be disregarded because it is of low quality. In case of this experiment, we can analyze the separate effect of advice but at the expense of controlling for the latter, quality aspect.

The situation is different when the advice originates from traffic management. In that case, the advice provides information about consequences of choices for traffic conditions on the road network. This will have an influence on choice behavior to the extent that the individual is concerned with system consequences of his/her behavior. Thus, by including this condition we can test the extent to which drivers are sensitive to environmental objectives. 


\section{Context variables}

Characteristics of the trip, such as trip purpose, time constraints and accompanying persons, can have an influence on the perceived utilities of the different attributes. In the experiment, the following four trip settings are varied as context variables:

- Work - fixed work start time: direct trip from home to the work address. There is some pressure of time in this situation, as the arrival time (work starting time) is fixed, but the departure time is flexible. The trip is part of a daily routine and is made by the driver alone - there are no other passengers in the car.

- Work - flexible work start time: similar as the previous trip, but now the arrival time (work start time) is flexible. This leads to less time pressure.

- Visit family or friends: this trip is supposed to be made with about four persons (family or friends) in the car, to visit other family or friends at their home in another city for one day as a daytrip. An arrival time is agreed, but this is not very strict.

- Shopping: the purpose of this trip is to go shopping in a city for one afternoon for fun (recreational shopping). It's done on a free day, and there is not much time pressure. The trip is supposed to be made with two or three people in the car.

\section{Experimental design}

Choice alternatives are constructed based on a factorial design that allows estimating the main effects of the involved attributes. Because possible interaction effects are left out of consideration, an orthogonal fraction of 18 profiles of a full factorial design suffices to estimate the main effects. The design allows us to estimate main effects of attributes. Possible interaction effects, such as for example an interaction between travel-time and comfort outcomes of routes cannot be estimated based on this design, but are neither critical for the behavior we want to analyze. Each choice-set presented to respondents includes two route alternatives. To compose the choice-sets, route profiles are randomly selected from the set of 18 profiles. Furthermore, a context setting (trip setting) is randomly selected for each choiceset generated. Finally, each respondent is randomly assigned to one of the 5 distinguished route-advice conditions.

\section{Presentation of choice alternatives}

Figure 1 shows an example of how choice sets are presented to the respondents. The two route alternatives are presented on a map. Above the map the trip setting (context) is described, and for the group of respondents who receive advice, also an advice for one of the two route options is shown. The map gives a schematic view of the two route options (A and B) in line with the specific attributes of the routes. Attribute levels are represented verbally on the left and right panes of the picture.

$<$ insert Figure 1 around here $>$

\section{SAMPLE AND ADMINISTRATION}

The experiments are presented to the respondents using an on-line questionnaire. This way of data collection is chosen over a paper and pencil questionnaire, because it makes it possible 
to reach many respondents in an efficient way. The survey was conducted in the Netherlands. Because a large portion of Dutch citizens, and possibly even a larger portion of the car drivers, have currently the availability of internet it is possible to sample from a quite general population. The target population includes all car drivers that may or may not use an in-car navigation system.

Respondents were recruited by delivering invitations to fill out the questionnaire on internet door-by-door in neighborhoods of Nijmegen and Malden - a middle-sized city and a local town in The Netherlands respectively. An additional number of 330 people who participated in an earlier survey were approached by email with a link to the website of the questionnaire. In total, the website with the questionnaire is visited 262 times between $8^{\text {th }}$ of June and $22^{\text {nd }}$ of July 2010. Of these visitors, 246 have completed the first page with personal questions (6 of them had no driver's license for a car and could therefore not continue), whereas the second page with questions about personal travel behavior is filled out 236 times. A total of 209 respondents completed the entire questionnaire and are used in the analysis here. Respondents were randomly assigned to one of the five advice conditions. The groups are of equal size except that the no-advise group was intentionally larger (77 persons).

The first section of the questionnaire is designed to collect background information about socio-demographics, work status, travel behavior and use of travel information systems. Participants who answer to have no driver's license for a car do not further proceed. The main part of the questionnaire is the stated choice experiment. After an explanation of the task, each participant is presented a random set of ten choice sets. In every choice set, the respondent is asked to choose one of the two route options that best reflects his or her preferences. The choice experiment is followed by a subexperiment that is included to identify individuals' perceptions of the used quality labels as a function of observable route characteristics (not further detailed here).

\section{RESULTS}

\section{Sample characteristics}

The sample shows a small overrepresentation of male respondents: $57 \%$ of the respondents are male and $43 \%$ female. All age classes are well represented, although the number of participants of 65 years of age and older is relatively small. In terms of work status, $78 \%$ of the respondents indicate that their main daily activity is paid work (56\% full-time, $22 \%$ parttime). About 80 percent of the participants state that there is (almost) always a car available for them. For less than two percent of the respondents a car is never available. The total distance travelled by car as driver or passenger per year is for only 14 percent of the respondents less than 5000 kilometers. Most respondents have (almost) always (39\%) or (almost) never (33 \%) an in-car navigation system available for car trips. The trip purpose with the highest proportion of navigation system usage is on holiday. Also on business trips the use of navigation systems is quite high, whereas the number of people that use the navigation device "sometimes" is high on trips for visits and drop off/pick up a person.

\section{Estimation results}

A panel Mixed Multinomial Logit model is used to analyze the stated choice data using the software Biogeme 2.0 (18). For the travel-time attribute, the difference in time between the two route alternatives (in every choice situation) is considered more relevant than the absolute travel time. For this reason, the travel time is recoded into a new variable that represents a difference with the shortest route (least travel time route). As a result, the possible levels of the relative travel time is "shortest" (shorter or same time as the other route 
in this choice situation), "+5 minutes" (travel time 5 minutes more than the other route option) or +10 minutes. The other attributes can be interpreted independently of the other route option and therefore there is no advantage in recoding them. Effect coding was used for all attributes to estimate effects of attribute levels relative to an average. Consistently, the middle level was chosen as base.

In addition to main effects, interactions between the context variable (a 4 level variable) and all attribute variables were tested. Only the interaction effects that were significant were included in the final specification of the model. To account for possible unobserved taste heterogeneity, distributions were estimated for attribute parameters assuming a normal form of the distribution. Presence of unobserved taste heterogeneity was tested in an initial phase. This involved estimating a standard deviation for one attribute (main effect) at a time. Only for those attributes where the standard deviation was significant random parameters were assumed in the final estimation of the model. The number of draws was set to 1000. Errors were drawn from a normal distribution using a pseudo-random number generator in Biogeme. To analyze the influence of advice, a scale parameter was estimated for each group that received route advice of some type. The scale parameter represents the scale of attribute utility effects relative to the group that did not receive advice. As explained before, we test for each advice group whether the scale is smaller than one (there is an influence of advice). We emphasize that the scale parameter in the context of a logit model effectively represents the concept that we intend to measure. In a logit model, the scale parameter represents the scale of the systematic utility relative to the scale of error variance. In the context of our experiment, an increase of error can indeed be attributed as an effect of advice: the recommendation of an alternative is completely random, so that following advice means that the resulting choices are random. Hence, a decrease of the scale parameter between a group that received advice and the group that did not receive advice can be interpreted here as compliance to advice to the degree of the decrease.

Table 2 shows the estimation results of the model. A rho-square (adjusted) of 0.249 indicates a satisfactory goodness-of-fit of the model. All attribute main effects are significant and have signs as expected. Since effect coding is used the beta parameters add up to unity across the levels of an attribute. On this basis, the beta parameter of the middle category, which was used as base level, for each attribute can be calculated given estimates of beta's for the other levels. The table shows the estimated as well as the calculated values (the latter have no p-value associated to them).

\section{$<$ insert Table 2 around here>}

Travel time of the trip (travel time and delay attributes) and costs are the most important attributes in the route choice, as could be expected. As for the remaining attributes, the importance of safety is relatively high. Particularly, the negative utility of an unsafe route (level E) is very high. The scenery of the routes is the least important attribute for route choice. The burden the trip imposes on the environment also has a significant influence on utility of a route. Figure 2 shows the main effects graphically. Several context variables are significant else well. When the trip purpose is social visit or shopping the influence of travel time difference on route choice is considerably smaller than when the purpose is work. For social-visit trips the importance of comfort is higher. The estimates of standard deviations indicate that unobserved taste heterogeneity is significant only at the level of costs and environmental burden. 
The estimates of the scale parameters indicate low degrees of compliance with route advice in general. Interestingly, there is only a significant impact of personalized advice provided by traffic management, i.e. advice that serves the goals of traffic management and at the same time takes personal preferences of the driver into account. A scale parameter of 0.57 indicates that, under that condition, the suppression of utility differences in terms of the attributes is substantial but at the same time far from complete: being the advised route has a relative weight of 0.43 in the overall evaluation of a route. All other types of advice have no significant impacts on the route choice. This finding is contrary to our hypotheses. That is to say, as a tendency, we do see, in line with expectations, that personalized advice has a higher impact than non-personalized advice. However, the expectation in terms of agency is contrary to what we expected: individuals are inclined to comply more strongly with advice when the purpose is traffic management than when it is supposed to be focused on the individual objectives of the driver. This can be attributed to the rich information condition: when individuals receive extensive information about the outcomes of route alternatives they discard advice. Thus, the result indicates that travelers are not inclined to follow advice blindly, at least not when a strong correlation with own preferences is absent.

The scale parameter represents an overall suppression effect of advice on utility differences between route alternatives. In theory, advice could have differential impacts in the sense that it influences utility evaluations regarding specific route attributes. To test such a differential impact, we conducted a further analysis where we estimated interaction effects between advice condition and attributes of route alternatives in a model without scale parameters. Results are shown in Table 3 (only significant interactions are shown).

<insert Table 3 around here $>$

In this model specification, the scale parameters are replaced by specific parameters for the interaction between group and attributes. The adjusted rho-square of this model is 0,245 (compared to 0.249 for the previous specification). Only traffic managementpersonalized advice has significant interaction effects with attributes (the only exception is that there is also a significant effect of a non-personalized form of traffic management advice, namely on Environment). This is in line with the earlier finding that only this advice condition has an impact on the scale of utilities. The first attribute with a different evaluation in this group compared to the no-advice group is travel time. For this group, the negative utility for the alternative with the longest travel time is considerably higher than for the participants getting no advice. On the other hand, the negative utility for the alternative with the longest delay is considerably lower for this group. A possible explanation for this is that drivers receiving personal advice from traffic management assume that the delay has been considered by the agency and is therefore easier to accept. Another attribute that shows a significant interaction is comfort of the route. Drivers receiving personalized advice from traffic management assign lower importance to comfort of the route. At the same time, the importance of "environment and burden" is higher for the group getting this kind of advice. A possible explanation is that drivers want to compensate for the fact that this advice type ignores environmental impacts by raising their own utility for this attribute. In sum, these findings indicate that there is a differential impact of advice on attribute evaluations in addition to a general scale effect. Some attributes become even more important compared to the group that does not receive advice.

\section{Discussion}

Our hypotheses are only partly confirmed: advice that is said to be personalized has a larger impact than advice that is supposed to be non-personalized (expected), but advice from traffic 
management has a bigger impact than advice from a navigation system that is supposed to advice what is best for the individual (unexpected). As said, a likely explanation for this finding is that, in the experiment, advice is given under rich information conditions. Since individuals received information on a number of attributes that are relevant to them, they could determine their own preferences to a large extent. Under that condition, advice from traffic management is complementary, whereas advice from an individual perspective is redundant or overruled. We emphasize that this assumption of rich information (or rich knowledge) is not an unrealistic feature of the experiment. Available travel information systems increasingly create such conditions in a pre-trip (route planners) or en-route stage (navigation systems). At the same time, it is representative for drivers that do not use the systems but have extensive routing knowledge for the trip. However, an unrealistic feature of the experiment on this level is that advice does not correlate with shown performance of routes (since it is random) and, hence, individuals could have discarded the advice when learned that its quality is poor. On the other hand, the results suggest that compliance with advice from traffic management under rich information conditions is far from perfect. In a substantial proportion of cases drivers overrule advice and follow the route of their own preference. Interestingly, advice does not have a uniform effect on how drivers evaluate attributes. On the one hand, they are willing to accept lower preference levels related to delays and comfort, but, on the other hand, travel time and environmental impact become more salient in their evaluations. Thus, the results suggest that advice does not merely suppress but also change the way drivers evaluate route alternatives. This might be due to compensation for biases they assign to the agency providing the advice. A significant effect of Environment and burden indicates that drivers are willing to take into account social objectives in their route choice.

\section{CONCLUSIONS AND DISCUSSION}

In this study we described the results of a stated choice experiment conducted to investigate drivers' compliance with route advice and willingness to take into account social objectives in route choice. The experiment involved a representative sample of car drivers from the Netherlands. We investigated compliance for different types of advice in terms of the goal of the agency providing the advice (traffic management or personal objectives) and extent to which it uses information of specific preferences of the person (personalized or generic advice). In the experiment, respondents obtained information about a number of attributes of route alternatives in each choice task presented mimicking a situation where the driver uses an advanced travel information system. The information system also provided information about possible negative environmental impacts (social objective).

The findings suggest that drivers' propensity to comply with advice is far from complete. Drivers take into account the objectives of the agency providing the advice and the extent to which personal preferences are incorporated. Under rich information conditions, advice focused on a person's own individual objectives is overruled. Drivers are willing to follow advice from traffic management and to trade-off social objectives with individuallevel objectives to some extent. This indicates that we may expect an influence of travel information systems that provide feedback on impacts on the environment of trips. Compliance with advice from traffic management is not unconditional. Drivers are willing to accept advice only if they know that also personal objectives are taken into account. This is a clear message for the design of distributed-advice systems: compliance is limited and an important condition for acceptance is that personal interests are taken into account as well. 
Furthermore, our findings suggest that advice has a differential impact on how attributes of alternatives are evaluated.

These findings are informative for design of travel information systems and assessment of system consequences of these systems. However, further research is needed. First, we did not consider possible effects of socio-demographic variables (such as gender and age) on behavior. In future research, the analysis should be extended to also include socio-demographic variables and possibly other personal background variables as independent variables. Second, it is interesting to analyze the effect of learning across repeated choices of an individual. Third, the present experiment assumed rich information conditions. It would be interesting to vary this aspect in future experiments and analyze individuals' preferences for information/advice condition simultaneously with their choice behavior. When individuals have a choice between receiving recommendations (advice) or information (attributes) they may trade-off cognitive costs of evaluation (information) against a risk of following suboptimal advice. Furthermore, the interactions between advice and information, which we found in the present study, raise questions that need to be investigated further.

\section{ACKNOWLEDGEMENTS}

The research leading to these results has received funding from the European Community's Seventh Framework Program (FP7/2007-2013) under the Grant Agreement number 234239. The authors are solely responsible for the information reported in this paper. It does not represent the opinion of the Community. The Community is not responsible for any use that might be made of the information contained in this paper.
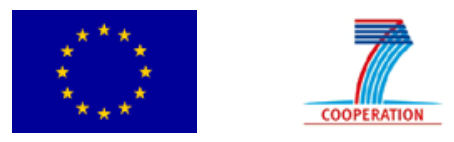

\section{REFERENCES}

1. Chorus, C.G., E.J.E. Molin van B. van Wee. Travel Information as an Instrument to Change Car-Drivers' Travel Choices: A Literature Review. In European Journal of Transport and Infrastructure Research, Vol. 6, No. 4, 2006, pp. 335-364.

2. Bonsall, P., and Parry T. Using an Interactive Route-Choice Simulator to Investigate Drivers' Compliance with Route Guidance Advice. In Transportation Research Record: Journal of the Transportation Research Board, No. 1306, Transportation Research Board of the National Academies, Washington, D.C., 1991, pp. 59-68.

3. Yang, H., R. Kitamura, P.J. Jovanis, K.M. Vaughn and M.A. Abdel-Aty. Exploration of Route Choice Behavior with Advanced Traveler Information Using Neural Network Concepts. In Transportation, Vol. 20, No. 2, 1993, pp. 199-223.

4. Srinivasan, K.K., and H.S. Mahmassani. Modeling Inertia and Compliance Mechanisms in Route Choice Behavior Under Real-Time Information. In Transportation Research Record: Journal of the Transportation Research Board, No. 1725/2000, Transportation Research Board of the National Academies, Washington, D.C., 2007, pp. 45-53. 
5. Shen-Te Chen, P., K.K. Srinivasan, and H.S. Mahmassani (2007). Effect of Travel Information Quality on Compliance Behavior of Commuters Under Real-Time Information. In Transportation Research Record: Journal of the Transportation Research Board, No. 1676/1999, Transportation Research Board of the National Academies, Washington, D.C., 2007, pp. 53-60.

6. Fox, J.E., and D.A. Boehm-Davis. Effects of Age and Congestion Information Accuracy of Advanced Travel Information Systems on User Trust and Compliance. In Transportation Research Record: Journal of the Transportation Research Board, No. 1621/1998, Transportation Research Board of the National Academies, Washington, D.C., 2007, pp. 43-49.

7. Chorus, C.G., T.A. Arentze and H.J.P. Timmermans. Traveler' Compliance With Advice: a Bayesian Utilitarian Perspective. In Transportation Research Part E, Vol. 45, No. 3, 2009, pp. 486-500.

8. Sunitiyoso, Y., E. Avineri, K. Chatterjee. The Effect of Social Interactions on Travel Behaviour: An Exploratory Study Using a Laboratory Experiment. In Transportation Research Part A, Vol. 45, No. 4, 2011, pp. 332-344.

9. Eriksson, L., S.E. Forward. Is the Intention to Travel in a Pro-Environmental Manner

1. and the Intention to Use the Car Determined by Different Factors? In Transportation Research Part D, Vol. 16, No. 5, 2011, pp. 372-376.

10. Ben-Elia, E., D. Ettema. Rewarding Rush-Hour Avoidance: A Study of Commuters' Travel Behavior. In Transportation Research Part A, Vol. 45, No. 7, 2011, pp. 567-582.

11. Loukopoulos, P., C. Jakobsson, T. Gärling, C.M. Schneider, S. Fujii. Public Attitudes Towards Policy Measures for Reducing Private Car Use: Evidence from a Study in Sweden. In Environmental Science and Policy, Vol. 8, No. 1, 2005, pp. 57-66.

12. Han, Q., H.J.P. Timmermans, B.G.C. Dellaert and F. van Raaij. Route Choice under Uncertainty: Effects of Recommendation. CD-ROM. In Proceedings of the 87th Annual Meeting of the Transport Board, Washington DC, 2008.

13. Papinski, D., D.M. Scott and S.T. Doherty. Exploring the Route Choice Decision-Making Process: A Comparison of Planned and Observed Routes Obtained Using Person-Based GPS. In Transportation Research Part F: Traffic Psychology and Behaviour, Vol. 12, No. 4, 2009, pp. 347-358.

14. Bovy, P. H., and E. Stern. Route Choice: Wayfinding in Transport Networks. Kluwer Academic, Dordrecht, Netherlands, 1990.

15. Golledge, R. G. Wayfinding Behavior: Cognitive Mapping and Other Spatial Processes, John Hopkins University Press, Baltimore, US, 1999.

16. Chen, T-Y., H-L. Chang and G-H. Tzeng. Using a Weight-Assessing Model to Identify Route Choice Criteria and Information Effects. In Transportation Research Part A, Vol. 35, No. 3, 2001, pp. 197-224. 
17. Golledge, R.G. and T. Garling. (2002) Spatial Behaviour in Transportation Modeling and Planning. In Transportation systems planning: methods and applications (K. Goulias, ed.), CRC Press, New York, 2002, pp. 3-1 to 3-21.

18. Bierlaire, M. Estimation of discrete choice models with BIOGEME 1.8: Manual. Ecole Polytechnique Federale de Lausanne, Switzerland, 2009. 


\section{List of tables}

TABLE 1 Attributes and Levels Varied in the Route Choice Experiment

TABLE 2 Estimation Results

TABLE 3 Estimation Results: Interactions Between Route Advice Condition and Attributes

\section{List of figures}

FIGURE 1 Example of Graphical Representation of a Choice-Set

FIGURE 2 Utility of Attribute Levels 
TABLE 1 Attributes and Levels Varied in the Route Choice Experiment

\begin{tabular}{|c|c|c|c|}
\hline \multirow{2}{*}{ Variables } & \multicolumn{3}{|c|}{ Levels and their coding } \\
\hline & No. & Levels & Coding \\
\hline \multicolumn{4}{|l|}{ Attribute variables } \\
\hline \multirow{3}{*}{ Travel time } & (1) & 25 minutes & - \\
\hline & (2) & 30 minutes & - \\
\hline & (3) & 35 minutes & - \\
\hline \multirow[t]{3}{*}{ Estimated delay } & (1) & Delay not likely & $(1,0)$ \\
\hline & (2) & 5 minutes delay & $(-1,-1)$ \\
\hline & (3) & 10 minutes delay & $(0,1)$ \\
\hline \multirow[t]{3}{*}{ Trip price } & (1) & $€ 5,70$ & $(1,0)$ \\
\hline & (2) & $€ 7,65$ & $(-1,-1)$ \\
\hline & (3) & $€ 10,05$ & $(0,1)$ \\
\hline \multirow[t]{3}{*}{ Comfort } & (1) & Level A (comfortable) & $(1,0)$ \\
\hline & (2) & Level C & $(-1,-1)$ \\
\hline & (3) & Level E (uncomfortable) & $(0,1)$ \\
\hline \multirow[t]{3}{*}{ Scenery } & (1) & Level A (beautiful) & $(1,0)$ \\
\hline & (2) & Level C & $(-1,-1)$ \\
\hline & (3) & Level E (awful) & $(0,1)$ \\
\hline \multirow[t]{3}{*}{ Environment and burden } & (1) & Level A (friendly) & $(1,0)$ \\
\hline & (2) & Level C & $(-1,-1)$ \\
\hline & (3) & Level E (unfriendly) & $(0,1)$ \\
\hline \multirow[t]{3}{*}{ Safety } & (1) & Level A (safe) & $(1,0)$ \\
\hline & (2) & Level C & $(-1,-1)$ \\
\hline & (3) & Level E (unsafe) & $(0,1)$ \\
\hline \multirow[t]{5}{*}{ Route advice } & (1) & No advise & $(1,0,0,0)$ \\
\hline & (2) & In-car navigation system - personalized & $(0,1,0,0)$ \\
\hline & (3) & In-car navigation system - generic & $(-1,-1,-1,-1)$ \\
\hline & (4) & Traffic management - personalized & $(0,0,1,0)$ \\
\hline & (5) & Traffic management - generic & $(0,0,0,1)$ \\
\hline \multicolumn{4}{|l|}{ Context variables } \\
\hline \multirow[t]{4}{*}{ Trip type } & (1) & $\begin{array}{l}\text { From home to work - flexible work starting } \\
\text { time }\end{array}$ & \\
\hline & $(2)$ & $\begin{array}{l}\text { From home to work - fixed work starting } \\
\text { time }\end{array}$ & \\
\hline & (3) & Visit family or friends & \\
\hline & (4) & Shopping & \\
\hline
\end{tabular}


TABLE 2 Estimation Results

\begin{tabular}{|c|c|c|c|}
\hline Attributes & Level & $\boldsymbol{\beta}$ & p-value \\
\hline \multirow[t]{3}{*}{ Travel time (difference) } & shortest & 0.798 & 0.00 \\
\hline & +5 minutes & 0.272 & - \\
\hline & +10 minutes & -1.07 & 0.00 \\
\hline \multirow[t]{3}{*}{ Delay } & no delay & 0.533 & 0.00 \\
\hline & 5 minutes & 0.089 & - \\
\hline & 10 minutes & -0.622 & 0.00 \\
\hline \multirow[t]{3}{*}{ Costs } & $€ 5,70$ & 1.05 & 0.00 \\
\hline & $€ 7,65$ & 0.08 & - \\
\hline & $€ 10,05$ & -1.13 & 0.00 \\
\hline \multirow[t]{3}{*}{ Comfort } & A & 0.626 & 0.00 \\
\hline & $\mathrm{C}$ & -0.071 & - \\
\hline & E & -0.555 & 0.00 \\
\hline \multirow[t]{3}{*}{ Scenery } & A & 0.359 & 0.00 \\
\hline & $\mathrm{C}$ & 0.004 & - \\
\hline & E & -0.363 & 0.00 \\
\hline \multirow[t]{3}{*}{ Environment and burden } & A & 0.605 & 0.00 \\
\hline & $\mathrm{C}$ & -0.051 & - \\
\hline & E & -0.554 & 0.00 \\
\hline \multirow[t]{3}{*}{ Safety } & A & 0.594 & 0.00 \\
\hline & $\mathrm{C}$ & 0.265 & - \\
\hline & E & -0.859 & 0.00 \\
\hline \multicolumn{2}{|l|}{ Context variables (trip purpose) } & $\boldsymbol{\beta}$ & p-value \\
\hline \multicolumn{2}{|l|}{ Safety (level 1) × work flexible } & 0.215 & $0.07 *$ \\
\hline \multicolumn{2}{|l|}{ Travel time (level 1) $\times$ visit } & -0.357 & 0.01 \\
\hline \multicolumn{2}{|l|}{ Travel time (level 3) × visit } & 0.622 & 0.01 \\
\hline \multicolumn{2}{|l|}{ Comfort (level 3) × visit } & -0.347 & 0.01 \\
\hline \multicolumn{2}{|l|}{ Travel time (level 1 ) $\times$ shopping } & -0.501 & 0.00 \\
\hline \multicolumn{2}{|l|}{ Travel time (level 3) $\times$ shopping } & 0.651 & 0.01 \\
\hline \multicolumn{4}{|l|}{ Standard deviations } \\
\hline \multicolumn{2}{|l|}{ Trip price (level 1) } & -0.298 & 0.02 \\
\hline \multicolumn{2}{|l|}{ Comfort (level 3) } & -0.237 & $0.11 *$ \\
\hline \multicolumn{2}{|l|}{ Environment and burden (level 3) } & 0.456 & 0.00 \\
\hline \multicolumn{2}{|l|}{ Scale parameters - advice condition } & value & p-value \\
\hline \multicolumn{2}{|l|}{ No advice } & 1.00 & - \\
\hline \multicolumn{2}{|l|}{ Navigation system, personalized } & 0.818 & $0.17 *$ \\
\hline \multicolumn{2}{|l|}{ Navigation system, generic } & 1.04 & $0.87 *$ \\
\hline \multicolumn{2}{|l|}{ Traffic management, personalized } & 0.571 & 0.00 \\
\hline \multicolumn{2}{|l|}{ Traffic management, generic } & 0.969 & $0.83 *$ \\
\hline Model specifications & & & \\
\hline Model & & mial Log & \\
\hline Number of draws (Psuedo-random) & & 1000 & \\
\hline LL(0) & & -1448.678 & \\
\hline Final LL $(\beta)$ & & -1061.01 & \\
\hline p2 & & 0.268 & \\
\hline p2 Adjusted & & 0.249 & \\
\hline
\end{tabular}

*not significant at a 5\% alpha level 
TABLE 3 Estimation Results: Interactions Between Route Advice Condition and Attributes

\begin{tabular}{lcc}
\hline Context variables (route advice) & $\beta$ & $\mathrm{p}$-value \\
\hline Travel time (level 3) $\times$ traffic management personal & -.394 & .0282 \\
Delay (level 3) $\times$ traffic management personal & .277 & .0283 \\
Comfort (level 1) $\times$ traffic management personal & -.409 & .0060 \\
Comfort (level 3) $\times$ traffic management personal & .385 & .0094 \\
Environment (level 1) $\times$ traffic management personal & .373 & .0052 \\
Environment (level 1) $\times$ traffic management not personal & .297 & .0112 \\
\hline
\end{tabular}




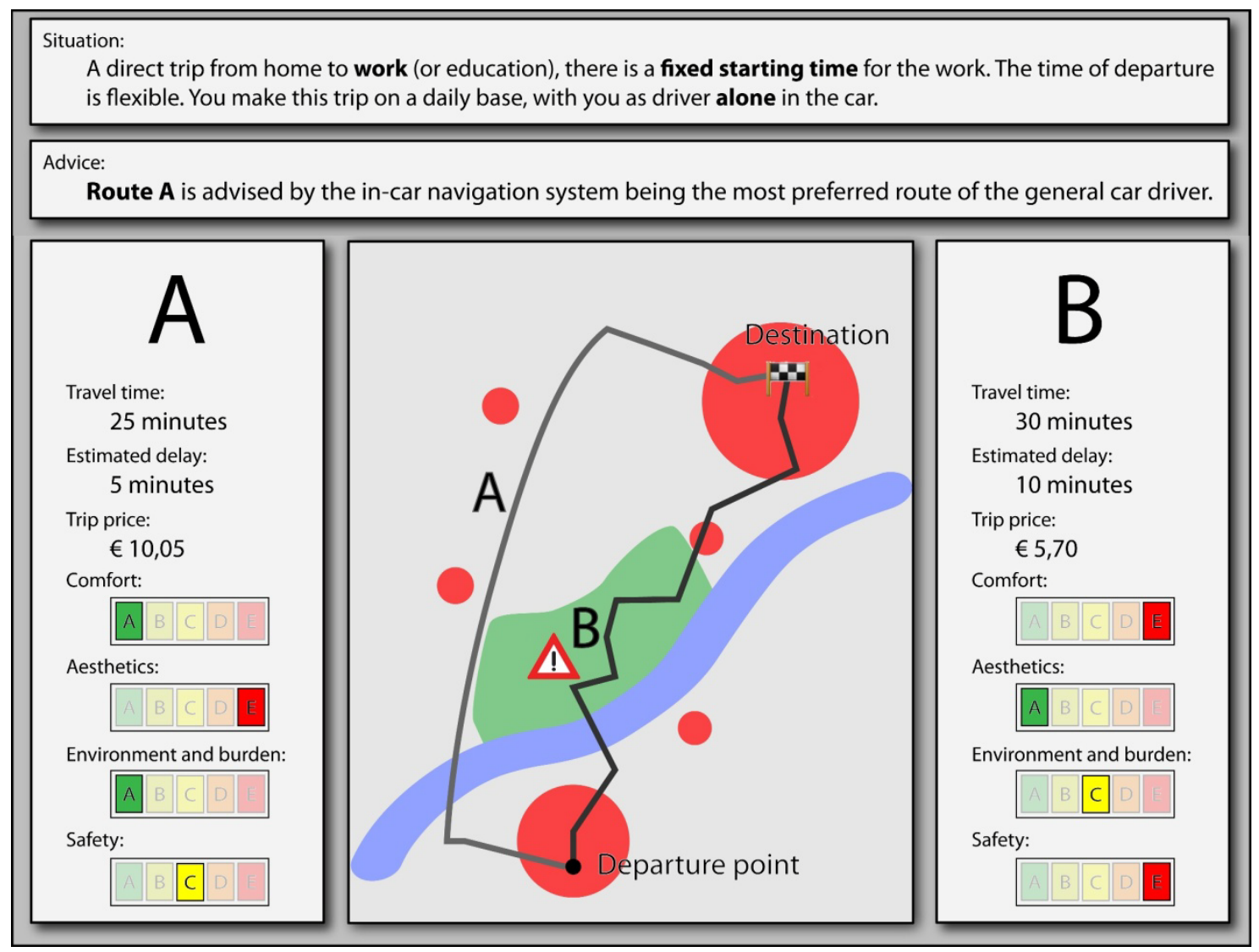

FIGURE 1 Example of Graphical Representation of a Choice-Set. 


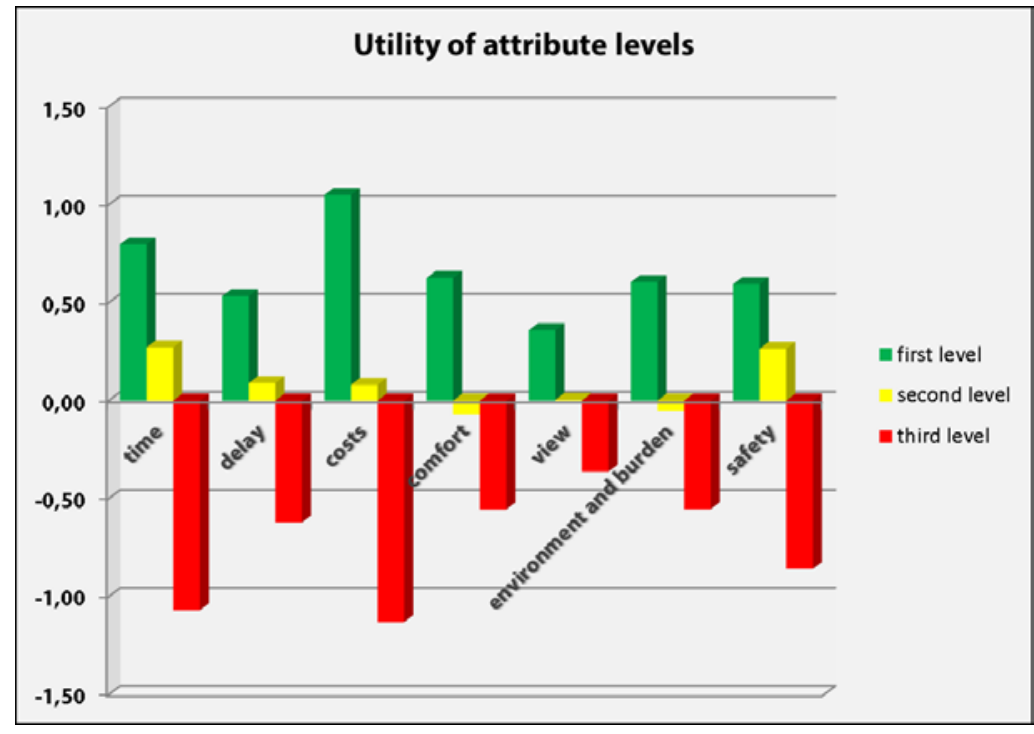

FIGURE 2 Utility of Attribute Levels. 